\title{
Effect of gestational diabetes and hypertensive disorders of pregnancy on postpartum cardiometabolic risk
}

\author{
Ling-Jun Li ${ }^{1,2,3}$, Izzuddin M Aris4, Lin Lin Su5, Yap Seng Chong ${ }^{4,5}$, Tien Yin Wong ${ }^{2,3}$, Kok Hian Tan ${ }^{1,2, *}$ \\ and Jie Jin Wang ${ }^{2, *}$ \\ 'Division of O\&G, KK Women's and Children's Hospital, Singapore, Singapore \\ ${ }^{2} O \& G$ ACP, Duke-NUS Graduate Medical School, Singapore, Singapore \\ ${ }^{3}$ Singapore Eye Research Institute, Singapore National Eye Centre, Singapore, Singapore \\ ${ }^{4}$ Singapore Institute for Clinical Sciences, Agency for Science Technology and Research (A*STAR), Singapore, Singapore \\ ${ }^{5}$ Department of O\&G, Yong Loo Lin School of Medicine, National University of Singapore, Singapore, Singapore \\ Correspondence should be addressed to L-J Li: queenie.li.I@kkh.com.sg \\ *(K H Tan and J J Wang contributed equally)
}

\begin{abstract}
Aims: The cumulative effect of gestational diabetes mellitus (GDM) and hypertensive disorders of pregnancy (HDP) on postpartum cardio-metabolic diseases is equivocal. We aimed to assess the associations of GDM and HDP's individual and synergic contribution to risks of postpartum cardio-metabolic diseases (metabolic syndrome (MetS), abnormal glucose metabolism and hypertension (HTN)).

Methods: Of participants from a Singapore birth cohort, 276 mothers attending the 5 -year postpartum visit were included in this study. During this visit, we collected mothers' history of GDM and HDP in all live births in a chronicle sequence and assessed the cardio-metabolic risks based on blood pressure, anthropometry and a panel of serum biomarkers. We diagnosed MetS, abnormal glucose metabolism and HTN according to Adult Treatment Panel III 2000 and World Health Organization guidelines.

Results: Of 276 mothers, 157 (56.9\%) had histories of GDM while 23 (8.3\%) had histories of HDP. After full adjustment, we found associations of GDM episodes with postpartum abnormal glucose metabolism (single episode: relative risk (RR) 2.9 (95\% Cl: 1.7, 4.8); recurrent episodes $(\geq 2): R R=3.8(2.1-6.8)$ ). Also, we found association between histories of HDP and HTN (RR=3.6 $(1.5,8.6))$. Having either (RR $2.6(1.7-3.9))$ or both gestational complications (RR 2.7 (1.6-4.9)) was associated with similar risk of postpartum cardiometabolic disease.

Conclusions: Mothers with GDM or HDP had a threefold increased risk of postpartum abnormal glucose metabolism or HTN, respectively. Having both GDM and HDP during past pregnancies was not associated with additional risk of postpartum cardio-metabolic diseases beyond that associated with either complication alone.
\end{abstract}

\section{Key Words}

- gestational diabetes mellitus

- hypertensive disorders of pregnancy

- cardio-metabolic disease

- metabolic syndrome

- hypertension

- abnormal glucose metabolism

\section{Introduction}

Gestational diabetes mellitus (GDM) and hypertensive disorders of pregnancy (HDP) are two of the most commonly seen pregnancy complications that adversely affect both short-term and long-term maternal and fetal outcomes $(1,2,3)$. The diagnosis of GDM identifies women with insulin resistance (targeted cell resistance to the http://www.endocrineconnections.org https://doi.org/10.1530/EC-17-0359
(C) 2018 The authors Published by Bioscientifica Ltd
Endocrine Connections (2018) 7, 433-442 
activity of insulin) and/or $\beta$-cell dysfunction (insufficient secretion of insulin by the pancreatic $\beta$-cells to compensate for peripheral insulin resistance) during pregnancy $(4,5)$. After pregnancy, GDM mothers are susceptible to progressive worsening in chronic $\beta$-cell defects, which is believed to mediate the development of recurrent GDM in subsequent pregnancy and postpartum type 2 diabetes (T2D) $(5,6,7)$. Consistent epidemiological evidence has shown that among mothers with prior history of GDM, $30-84 \%$ had GDM recurrence in subsequent pregnancies (8), 20-40\% developed metabolic syndrome (MetS) within 2-20 years $(9,10), 17-63 \%$ developed T2D within $5-16$ years $(11,12)$, and $10 \%$ developed renal disease within 11 years after delivery (13).

Interestingly, HDP including gestational hypertension, preeclampsia (PE) and eclampsia is more frequent among GDM mothers $(14,15)$. Studies suggested that gestational hypertension and PE were more likely to be an accompanying co-morbidity in pregnancies complicated with GDM, and could recur in subsequent pregnancies in mothers prior to $\operatorname{GDM}(16,17)$. Conditions associated with increased insulin resistance may predispose patients to essential hypertension, pregnancy-induced hypertension, hyperinsulinemia, hyperlipidemia and higher levels of plasminogen activator inhibitor-1, leptin and tumor necrosis factors-alpha $(16,18)$.

However, even though these two conditions may co-exist in the same or different pregnancies of the same mothers, evidence in the literature is inconsistent regarding whether or not co-existent GDM and HDP has a synergic effect to the risk of postpartum cardiometabolic disease (17). In a cohort of 276 mothers who had comprehensive data on history of GDM and HDP and full assessments on postpartum cardio-metabolic diseases, we aimed to investigate the following questions: The impact of recurrent GDMs, HDP or co-existence of both pregnancy complications, on the risk of postpartum cardio-metabolic diseases, including metabolic syndrome (MetS), abnormal glucose metabolism and hypertension (HTN).

\section{Methods}

\section{Study population and design}

This was a prospective study nested in an ongoing birth cohort in Singapore (Growing Up in Singapore Towards Healthy Outcomes, GUSTO). We previously reported the
GUSTO study design and recruitment criteria in detail (19). Of mothers who were recruited to the GUSTO during early trimester (5-8 weeks) of their baseline pregnancy, we intended to include 400 in this study; of whom 200 were diagnosed with GDM at baseline pregnancy, the remaining 200 were controls without GDM at baseline pregnancy, matched to GDM mothers for age, ethnicity and body mass index (BMI). This matched cohort of mothers with and without GDM was designed to investigate antenatal risk factors, and GDM particularly, associated with the development of postpartum cardio-metabolic diseases.

Inclusion criteria are (1) Mothers who attended both baseline and 5-year follow-up visits; (2) Mothers without chronic hypertension and/or diabetes at baseline recruitment and (3) Mothers who were not pregnant at the 5-year follow-up visit. Among 400 mothers originally selected from 1136 mothers in the GUSTO, 354 met the inclusion criteria. After excluding 47 mothers who declined participation and 31 who withdrew after consenting, a total number of 276 mothers (response rate $78.0 \%$ ) were included in this report (Fig. 1).

We diagnosed GDM as fasting glucose $\geq 7.0 \mathrm{mmol} / \mathrm{L}$ and/or 2-h glucose $\geq 7.8 \mathrm{mmol} / \mathrm{L}$ at 26 - to 28 -week gestation of baseline pregnancy, according to $1999 \mathrm{WHO}$ guideline via a $75 \mathrm{~g}$ oral glucose tolerance test (20).

We conducted the study according to the tenets of the Declaration of Helsinki and obtained approval by the SingHealth Centralized Institutional Review Board and the National Health Group's Domain Specific Review Board. We obtained written informed consents from all participants at the 5-year follow-up visit .

\section{Exposure: histories of GDM and HDP}

Trained staff administered a detailed pregnancy and birth outcomes questionnaire to all mothers attending the 5 -year follow-up visit. We recorded all past pregnancies including miscarriage, abortion, stillbirths and live births in a chronicle sequence. For all pregnancies, we collected time (in year format) and outcomes of each pregnancy. For live births, we further collected pregnancy complications of GDM and HDP (a cluster of gestational hypertension, preeclampsia and eclampsia) based on mothers' selfreporting.

We categorized GDM episodes into three groups: (1) Never; (2) One; (3) $\geq 2$ (recurrent). However, due to low number of HDP episodes, we dichotomized HDP into two groups only: (1) Never; (2) One or more.

$$
\begin{aligned}
& \text { http://www.endocrineconnections.org } \\
& \text { https://doi.org/10.1530/EC-17-0359 }
\end{aligned}
$$

(C) 2018 The authors Published by Bioscientifica Ltd
This work is licensed under a Creative Commons Attribution-NonCommercial-NoDerivatives 4.0 International License. 


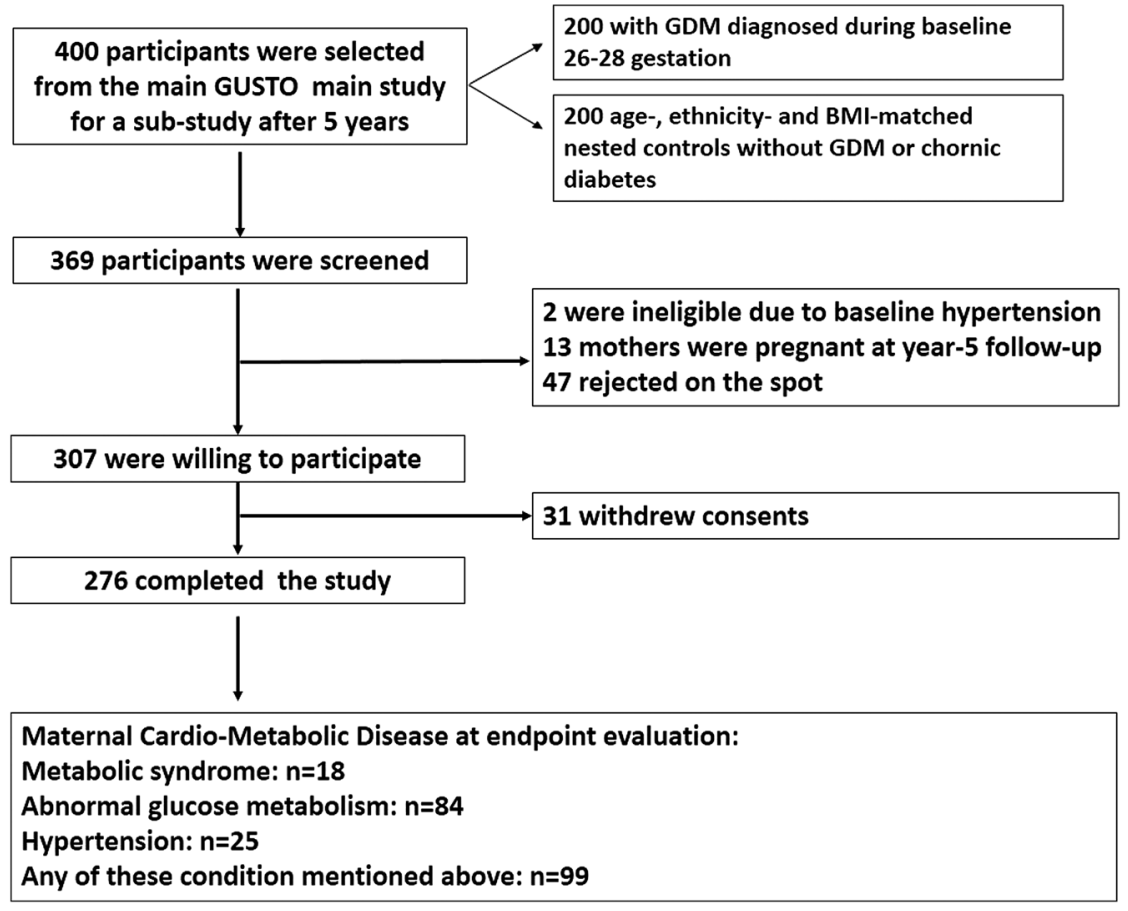

Figure 1

Flow chart of recruitment of our study of mothers.

\section{Outcomes: maternal postpartum cardio-metabolic disease}

All mothers underwent evaluation for metabolic outcomes. We measured blood pressure (BP), standing height and weight according to standardized protocols (19). We defined BMI as weight in $\mathrm{kg} /$ (height in $\mathrm{m}$ ). We measured waist circumference using a standard measuring tape. Furthermore, we conducted venepuncture and sent serum samples to the Singapore General Hospital laboratory for a panel of blood tests, including levels of cholesterol (highdensity lipoprotein (HDL), low-density lipoprotein (LDL) and triglyceride (TG)), glycemic status (75 g oral glucose tolerance test (OGTT), glycated hemoglobin (HbA1C) and insulin level) and C-reactive protein (CRP).

We applied Adults Treatment Panel (ATP) III 2000 to define postpartum MetS (21) when at least three of the four following components were met: (1) elevated BP: $\mathrm{SBP} \geq 130 \mathrm{mmHg}$ and/or $\mathrm{DBP} \geq 85 \mathrm{mmHg}$ or on antihypertensive medication; (2) abdominal obesity: waist circumference $>88 \mathrm{~cm}$; (3) dyslipidemia: $\mathrm{TG} \geq 1.7 \mathrm{mmol} / \mathrm{L}$ or $\mathrm{HDL}<1.3 \mathrm{mmol} / \mathrm{L}$ and (4) glucose intolerance: fasting plasma glucose $\geq 6.1 \mathrm{mmol} / \mathrm{L}$.

Furthermore, we defined following glucose abnormalities: (1) impaired fasting glucose (IFG) if fasting plasma glucose ranged between $6.1 \mathrm{mmol} / \mathrm{L}$ and $6.9 \mathrm{mmol} / \mathrm{L}$ (22); (2) impaired glucose tolerance (IGT) if fasting plasma glucose $<7.0 \mathrm{mmol} / \mathrm{L}$ and 2 -h plasma glucose between 7.9 and $11.0 \mathrm{mmol} / \mathrm{L}$ (22); (3) pre-diabetes

http://www.endocrineconnections.org https://doi.org/10.1530/EC-17-0359 when either of the following present: IFG, IGT or HbA1C between 5.7 and 6.4\% (23) and (4) type 2 diabetes (T2D) if fasting plasma glucose $\geq 7.0 \mathrm{mmol} / \mathrm{L}$ and/or 2 -h plasma glucose $\geq 11.0 \mathrm{mmol} / \mathrm{L}$ (22). We grouped both diagnosis of pre-diabetes and T2D as abnormal glucose metabolism.

We defined postpartum HTN by following criteria: (1) mothers who were free from chronic HTN during baseline visit and (2) mothers' SBP $\geq 140 \mathrm{mmHg}$ and/or DBP $\geq 90 \mathrm{mmHg}$ at follow-up visit or currently on antihypertensive medication (24).

\section{Other covariates}

Trained staff administered questionnaires in English, Chinese, Malay or Tamil at follow-up visit. We collected information on maternal education, household income, family history of diabetes, parity, pre-pregnancy weight, smoking and alcohol drinking in the past one year and physical activity in the past three months. Weight gain between baseline and follow-up visits (5-year interval) were calculated as the difference of weight at follow-up visit and pre-pregnancy weight.

\section{Statistical analysis}

We calculated the mean and standard deviation (s.D.) or median and inter-quartile range (IQR) based on the distribution of continuous variables. We presented 
baseline characteristics by postpartum cardio-metabolic diseases at follow-up visit: (1) MetS; (2) abnormal glucose metabolism; (3) HTN and (4) none of any of these cardiometabolic diseases mentioned above.

We applied multiple linear regression models to examine the associations between GDM or HDP and postpartum cardio-metabolic risks. We log-transformed fasting plasma insulin, 2-h plasma insulin, HOMA-IR, triglyceride (TG) and CRP due to their skewed distributions and reported the exponentiated parameter estimates from linear regression associations. We further applied modified Poisson regression models to examine the associations of recurrent GDM, HDP with postpartum MetS, abnormal glucose metabolism and HTN diagnosed at follow-up visit. We also assessed the associations of co-existing GDM and HDP with postpartum cardio-metabolic diseases (defined as having postpartum MetS, abnormal glucose metabolism or HTN). We applied the following three models for both linear regression and modified Poisson regression analyses: Model 1-unadjusted; Model 2-adjusted for maternal age, ethnicity, college education and pre-pregnancy BMI; Model 3-Model 2 and additionally adjusted for cumulative parity.

To test the robustness of our study findings, we performed sensitivity analyses by including the following co-variables in Model 3: family history of diabetes, smoking history, alcohol consumption and weight gain during the 5-year interval. We investigated the potential effect modification using multiplicative interaction terms of ethnicity with either gestational complication. Statistical analyses were conducted using STATA (version 14.0, STATA, Texas, USA). We provided 95\% confidence interval (CI) for all estimates and set a significant $P$ value at 0.05 .

\section{Ethics approval statements}

We conducted the study according to the tenets of the Declaration of Helsinki and obtained approval by the SingHealth Centralized Institutional Review Board and the National Health Group's Domain Specific Review Board. We obtained written informed consents from all participants at the 5-year follow-up visit.

\section{Results}

Among 276 mothers recruited in this study, there were 18 mothers (6.5\%) diagnosed with MetS, 84 (30.4\%) diagnosed with abnormal glucose metabolism, 25 (9.1\%) diagnosed with HTN and 99 (35.9\%) diagnosed with any of these postpartum maternal cardio-metabolic diseases (Table 1). Of mothers with past GDM, 123 (44.6\%) had only one GDM onset and 34 (12.3\%) had at least two onsets. The remaining 119 mothers (43.1\%) had no history of GDM. Of mothers with past HDP, 23 (8.3\%) had one or more onsets of gestational HTN, PE or eclampsia $(8.3 \%)$ (Table 1$)$.

Mothers who developed MetS, abnormal glucose metabolism or HTN tended to be older in age (38.9 vs 37.8 vs 39.2 vs 32.9 years), have higher pre-pregnancy BMI ( 28.6 vs 25.7 vs 27.2 vs $22.8 \mathrm{~kg} / \mathrm{m}^{2}$ ), higher frequencies of reporting previous GDM or HDP and higher levels of cardio-metabolic risk measures including fasting glucose level, SBP, insulin level, waist circumference and lipid biomarkers, compared with mothers without development of any of the cardiometabolic diseases (Table 1).

Table 2 shows the associations of cumulative episodes of GDM and HDP with maternal cardio-metabolic risks in multiple linear regression models. After adjusting for maternal age, ethnicity, college education (yes vs no), prepregnancy BMI and parity, the number of previous GDM had associations with lower postpartum BMI, higher fasting and 2-h glucose levels in a dose-response pattern. For example, mothers with one GDM episode $\left(-0.9 \mathrm{~kg} / \mathrm{m}^{2}\right.$ (95\% CI: $-1.6,-0.1)$ ) and at least two GDM episodes $\left(-11.4 \mathrm{~kg} / \mathrm{m}^{2}(-2.5,-0.3)\right)$ were associated with lower postpartum BMI ( $P$-trend $<0.01)$, respectively. Mothers with prior GDM were associated with higher postpartum fasting glucose levels (one GDM episode: $1.05 \mathrm{mmol} / \mathrm{L}$ (1.0, 1.1); $\geq 2$ GDM episodes: $1.07 \mathrm{mmol} / \mathrm{L}$ (1.0, 1.1), $P$-trend <0.001) and higher postpartum 2-h glucose levels (one GDM episode: $1.2 \mathrm{mmol} / \mathrm{L}(1.1,1.3) ; \geq 2$ GDM episodes: $1.3 \mathrm{mmol} / \mathrm{L}(1.2,1.4), P$-trend $<0.001)$. On the contrary, mothers with prior HDP were not associated with any of the metabolic risks measures, except for $\mathrm{BP}$ measures. Mothers with prior HDP were associated with both higher SBP $(9.9 \mathrm{mmHg}(4.3,15.5))$ and higher DBP (8.1 mmHg $(3.7,12.5)$ ) (Table 2 and Supplementary Table 1 , see section on supplementary data given at the end of this article).

We further applied modified Poisson regression model to assess the associations of cumulative GDM or HDP with individual postpartum cardio-metabolic diseases (Table 3). In the fully adjusted model, the relative risk (RR) (95\% CI) of developing postpartum abnormal glucose metabolism was higher in mothers with $\geq 2$ GDM episodes ( $R R=3.8$ $(2.1,6.8))$ than mothers with one episode of GDM $(\mathrm{RR}=2.9$ $(1.7,4.8))$, compared to mothers with no prior history of GDM ( $P$-trend <0.001). Mothers with prior HDP were at 


\begin{tabular}{|c|c|c|c|c|}
\hline Endocrine & L-J Li et al. & $\begin{array}{l}\text { Gestational diabetes and } \\
\text { metabolic diseases }\end{array}$ & $7: 3$ & 437 \\
\hline
\end{tabular}

Table 1 Characteristics of participants with postpartum cardio-metabolic outcomes in our cohort of mothers $(n=276)$.

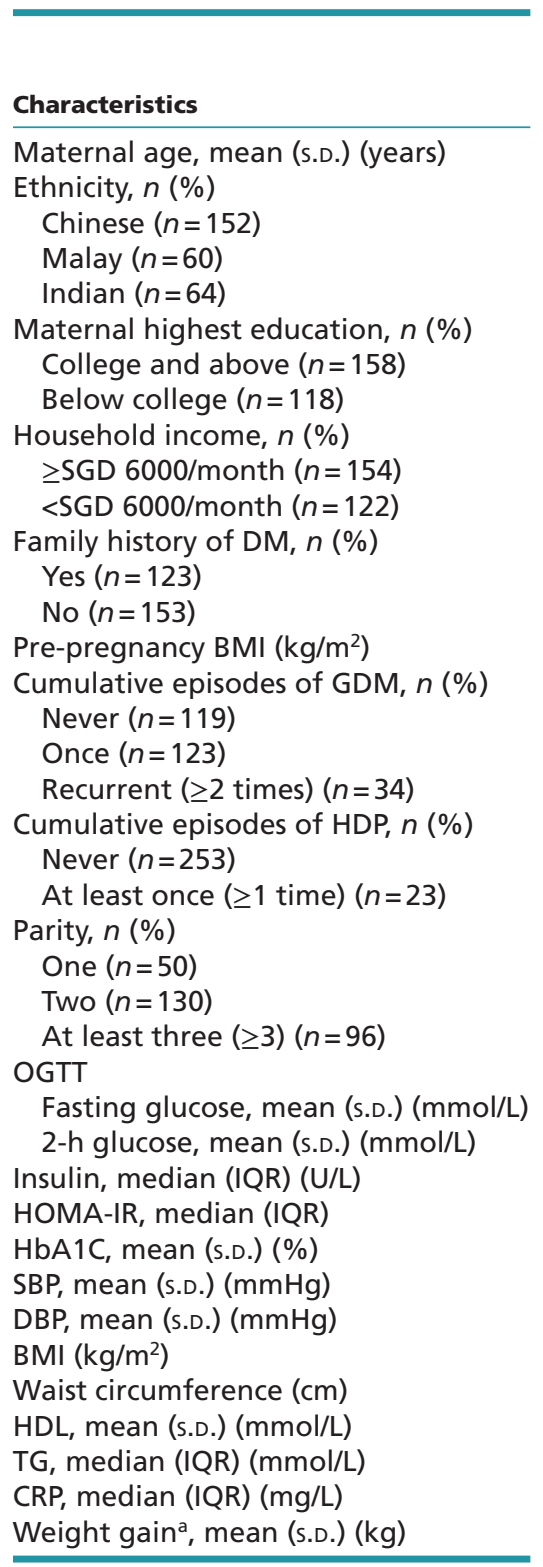

\begin{tabular}{c}
\hline Postpartum Mets \\
$(n=18)$ \\
\hline $38.8(5.6)$ \\
$10(6.6)$ \\
$4(6.7)$ \\
$4(6.3)$ \\
$14(8.9)$ \\
$4(3.4)$ \\
$14(9.1)$ \\
$4(0.8)$ \\
$12(9.8)$ \\
$6(4.0)$ \\
$28.6(2.8)$ \\
$4(3.4)$ \\
$12(9.8)$ \\
$2(5.9)$ \\
$12(4.7)$ \\
$6(26.1)$ \\
$2(4.0)$ \\
$5(3.8)$ \\
$11(11.5)$ \\
$5.5(1.4)$ \\
$9.9(3.3)$ \\
$11.8(6.1)$ \\
$2.7(1.8)$ \\
$5.8(0.7)$ \\
$131.7(15.5)$ \\
$82.6(11.6)$ \\
$30.4(3.0)$ \\
$98.2(7.8)$ \\
$1.1(0.2)$ \\
$1.4(0.9)$ \\
$5.3(7.0)$ \\
$7.14(8.9)$ \\
\hline
\end{tabular}

\begin{tabular}{c}
$\begin{array}{c}\text { Postpartum abnormal } \\
\text { glucose metabolism } \\
(n=84)\end{array}$ \\
\hline $37.8(4.9)$ \\
\\
$41(27.0)$ \\
$22(36.7)$ \\
$21(32.8)$ \\
$58(36.7)$ \\
$26(22.0)$ \\
\\
$54(35.1)$ \\
$30(24.6)$ \\
\\
$41(33.3)$ \\
$43(35.2)$ \\
$25.7(5.1)$ \\
$16(13.4)$ \\
$52(42.3)$ \\
$16(47.1)$ \\
$74(29.2)$ \\
$10(43.5)$ \\
$17(34.0)$ \\
$36(27.7$ \\
$31(32.3)$ \\
$5.3(1.1)$ \\
$9.8(2.6)$ \\
$8.9(7.8)$ \\
$1.9(2.0)$ \\
$5.7(0.7)$ \\
$70.6(13.7)$ \\
$27.6(6.1)$ \\
$90.3(13.0)$ \\
$1.3(0.3)$ \\
$1.2(0.8)$ \\
$3.2(7.6)$ \\
$5.8(8.2)$ \\
\hline
\end{tabular}

\begin{tabular}{c} 
Postpartum HTN \\
$(n=25)$ \\
\hline $39.2(4.9)$ \\
$14(9.2)$ \\
$7(11.7)$ \\
$4(6.3)$ \\
$18(11.4)$ \\
$7(5.9)$ \\
$20(13.0)$ \\
$5(4.1)$ \\
$13(10.6)$ \\
$12(7.8)$ \\
$27.2(4.1)$ \\
$7(5.9)$ \\
$15(12.2)$ \\
$3(8.8)$ \\
$16(6.3)$ \\
$9(39.1)$ \\
$4(8.0)$ \\
$5(3.8)$ \\
$16(16.7)$ \\
$5.1(0.8)$ \\
$8.3(3.4)$ \\
$8.5(5.2)$ \\
$1.8(1.2)$ \\
$5.5(0.4)$ \\
$85.2(16.0)$ \\
$28.1(4.8)$ \\
$91.8(12.2)$ \\
$1.3(0.3)$ \\
$1.4(1.0)$ \\
$3.5(6.0)$ \\
$4.1(7.9)$ \\
\hline
\end{tabular}

\begin{tabular}{c}
$\begin{array}{c}\text { Without any postpartum } \\
\text { cardio-metabolic } \\
\text { diseases }(n=177)\end{array}$ \\
\hline $32.9(4.8)$ \\
$104(68.4)$ \\
$33(55.0)$ \\
$40(62.5)$ \\
$89(56.3)$ \\
$88(74.6)$
\end{tabular}

aWeight gain $=$ (weight at follow-up visit) - (pre-pregnancy BMI).

$\mathrm{BMI}$, body mass index; CRP, C-reactive protein; DBP, diastolic blood pressure; DM, diabetes; GDM, gestational diabetes mellitus; HDL, high-density lipoprotein; HDP, hypertensive disorders of pregnancy; HTN, hypertension; IQR, inter-quartile range; MetS, metabolic syndrome; SBP, systolic blood pressure; S.D., standard deviation; TG, triglyceride.

an increased risk of developing postpartum MetS $(\mathrm{RR}=5.5$ $(2.3,13.3))$ and postpartum HTN $(\mathrm{RR}=6.2(3.1,12.4))$ in the unadjusted model. However, only the association with postpartum HTN remained significant after adjusting for maternal age, ethnicity, college degree, pre-pregnancy BMI and parity $(\mathrm{RR}=3.6(1.5,8.6))$ (Table 3$)$.

To assess the associations of either or combined GDM and HDP complications with postpartum cardio-metabolic diseases, we further applied modified Poisson regression models with any of the cardio-metabolic diseases as the

$\begin{array}{lr}\text { http://www.endocrineconnections.org } & \text { ○ } 2018 \text { The authors } \\ \text { https://doi.org/10.1530/EC-17-0359 } & \text { Published by Bioscientifica Ltd }\end{array}$

outcome variable. In a fully adjusted model, mothers with either or both of these conditions were associated with an increased risk of developing any of the cardio-metabolic diseases after delivery $(\mathrm{RR}=2.6(1.7,3.9)$ and $\mathrm{RR}=2.7(1.6$, $4.9)$, respectively) compared to mothers with neither GDM nor HDP (Table 4). These estimates and the 95\% CIs did not show increment between having either single and having combined complications in the past (Table 4).

Additional adjustment for maternal characteristics (e.g. family history of diabetes, smoking history and

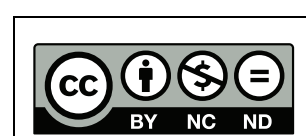
This work is licensed under a Creative Commons
Attribution-NonCommercial-NoDerivatives 4.0 International License. 


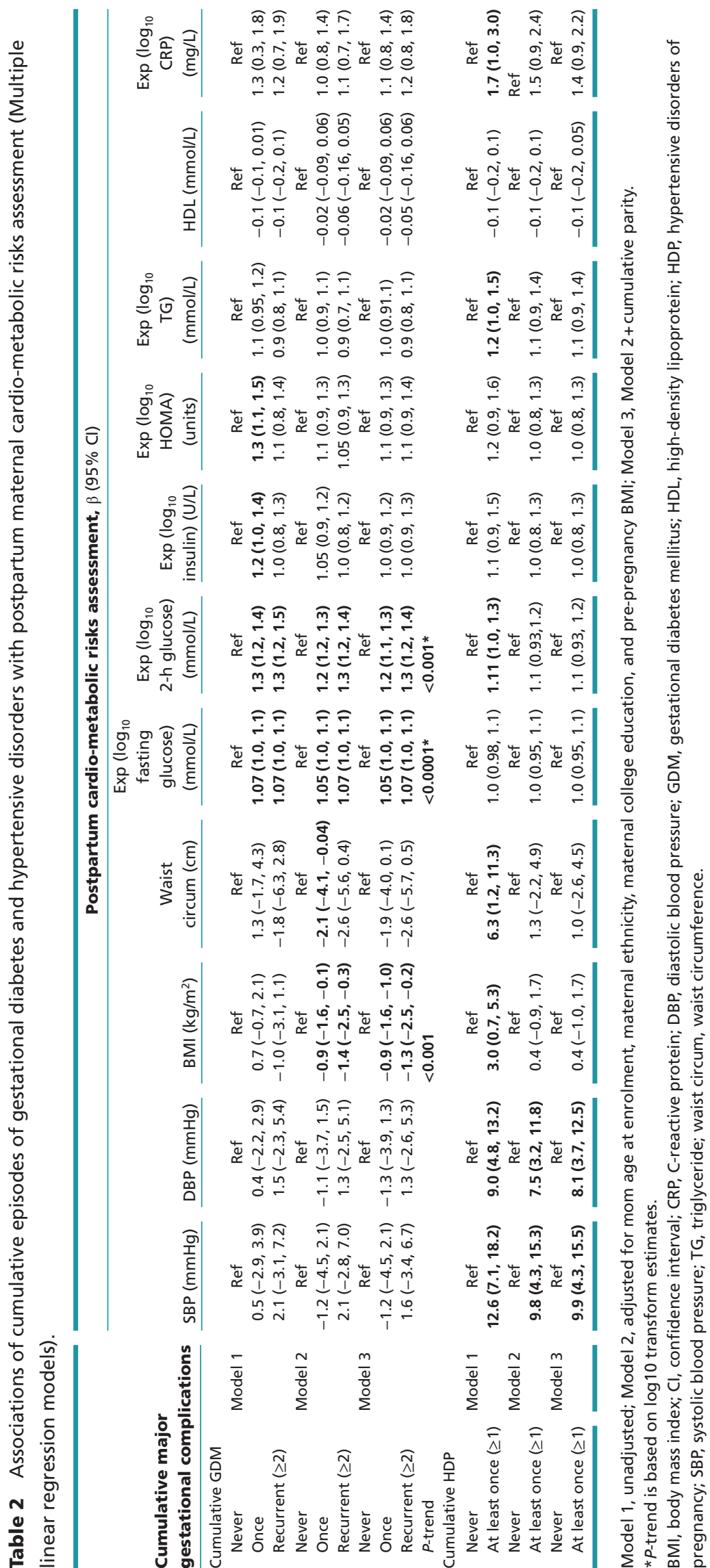


Table 3 Associations of cumulative episodes of gestational diabetes mellitus and hypertensive disorders with postpartum cardio-metabolic diseases (modified Poisson regression models).

\begin{tabular}{|c|c|c|c|c|}
\hline \multirow{2}{*}{\multicolumn{2}{|c|}{$\begin{array}{l}\text { Cumulative gestational complications collected at year } 5 \\
\text { follow-up visit }\end{array}$}} & \multicolumn{3}{|c|}{ RR $(95 \%$ Cl) } \\
\hline & & \multirow[t]{2}{*}{ Postpartum MetS Yes $(n=18)$} & \multirow[t]{2}{*}{$\begin{array}{c}\text { Postpartum glucose } \\
\text { abnormality Yes }(n=84)\end{array}$} & \multirow[t]{2}{*}{$\begin{array}{l}\text { Postpartum HTN } \\
\text { Yes }(n=25)\end{array}$} \\
\hline \multicolumn{2}{|l|}{ Cumulative GDM } & & & \\
\hline Never & Model 1 & Reference & Reference & Reference \\
\hline Once & & $2.9(1.0,8.8)$ & $3.1(1.9,5.2)$ & $2.1(0.9,4.9)$ \\
\hline Recurrent $(\geq 2)$ & & $1.8(0.3,9.2)$ & $3.5(2.0,6.2)$ & $1.5(0.4,5.5)$ \\
\hline Never & Model 2 & Reference & Reference & Reference \\
\hline Once & & $1.7(0.6,5.0)$ & $2.9(1.7,4.8)$ & $1.5(0.6,3.8)$ \\
\hline Recurrent $(\geq 2)$ & & $1.6(0.3,8.6)$ & $3.5(2.0,6.1)$ & $1.3(0.4,4.9)$ \\
\hline Never & Model 3 & Reference & Reference & Reference \\
\hline Once & & $1.7(0.5,5.5)$ & $2.9(1.7,4.8)$ & $1.6(0.6,4.1)$ \\
\hline \multirow[t]{2}{*}{ Recurrent $(\geq 2)$} & & $1.1(0.2,5.7)$ & $3.8(2.1,6.8)$ & $0.9(0.2,3.3)$ \\
\hline & & & $P$-trend $<0.001$ & \\
\hline \multicolumn{5}{|l|}{ Cumulative HDP } \\
\hline Never & Model 1 & Reference & Reference & Reference \\
\hline At least once $(\geq 1)$ & & $5.5(2.3,13.3)$ & $1.5(0.9,2.5)$ & $6.2(3.1,12.4)$ \\
\hline Never & Model 2 & Reference & Reference & Reference \\
\hline At least once $(\geq 1)$ & & $2.8(0.8,9.9)$ & $1.1(0.7,1.9)$ & $4.4(1.9,10.6)$ \\
\hline Never & Model 3 & Reference & Reference & Reference \\
\hline At least once $(\geq 1)$ & & $2.8(0.8,9.9)$ & $1.1(0.7,1.9)$ & $3.6(1.5,8.6)$ \\
\hline
\end{tabular}

Model 1, unadjusted; Model 2, adjusted for mom age at enrolment, maternal ethnicity, maternal college education, and pre-pregnancy BMI; Model 3, Model 2+cumulative parity.

$\mathrm{Cl}$, confidence interval; GDM, gestational diabetes mellitus; HDP, hypertensive disorders of pregnancy; HTN, hypertension; MetS, metabolic syndrome; $\mathrm{RR}$, relative risk.

weight gain between baseline recruitment and 5-year follow-up visit) did not appreciably change the associations observed. We found no evidence of effect modification by maternal ethnicity ( $P$-value in all interactions $>0.05)$ on the reported associations.

\section{Discussion}

In this cohort of mothers with and without GDM ( 1:1 ratio) at baseline, we found significant associations between the increased episodes of GDM and increased risk of postpartum abnormal glucose metabolism in a dose-response pattern and between HDP and the risk of postpartum HTN. Furthermore, mothers having either or both GDM and HDP in the past were at significantly higher risk of any postpartum cardio-metabolic diseases than mothers with neither gestational complications. However, no synergic effect of co-existing GDM and HDP on the risk of cardio-metabolic diseases was evident.

There is still paucity of studies assessing the effect of recurrent GDM on the development of postpartum cardio-metabolic diseases (17). A study conducted on a large population of women with prior GDM found a significant dose-response association between numbers of pregnancies with GDM and incident renal morbidity

$$
\begin{array}{lr}
\text { http://www.endocrineconnections.org } & \text { ○ } 2018 \text { The authors } \\
\text { https://doi.org/10.1530/EC-17-0359 } & \text { Published by Bioscientifica Ltd }
\end{array}
$$

after 11.2-year follow-up (13). The authors suggested that women with more episodes of GDM exhibited lower levels of plasma adiponectin, higher degrees of carotid intimalmedial thickness and subclinical inflammation, and thus, persistent generalized vascular dysfunction compared to women without or with fewer episodes of GDM (13). Conversely, a recent study of 72 mothers (41 with one episode of GDM, 21 with recurrent GDM, 10 healthy controls) yielded no evidence supporting a harmful effect of recurrent GDM on the 5-year deterioration of glucose metabolism, insulin sensitivity and secretion, nor on increased cardiovascular risks (25). The authors reported comparable degrees of weight retention after pregnancy and metabolic deterioration in both recurrent GDM and non-recurrent GDM groups (25). Some authors believed that impaired glucose tolerance and worsening insulin resistance were not caused by cumulative episodes of GDM in live births, but by the mother's weight retention entering the next pregnancy (26). Other researchers suggested that women prior to GDM could have modified their lifestyle between pregnancies or during their second pregnancy, resulting in weight loss or reduced weight gain during pregnancy, improved nutrition consumption and/or increased physical activity (27). Therefore, the risk of progression toward postpartum T2D might not be in a linear pattern, especially when observation was over short

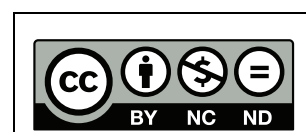
This work is licensed under a Creative Commons
Attribution-NonCommercial-NoDerivatives 4.0 International License. 
Table 4 Associations of individual or combined two major gestational complications (GDM and HDP) with any postpartum maternal cardio-metabolic diseases (modified Poisson regression models).

\section{Gestational major complications}

Without either major gestational complications $(n=115)$ With either major gestational complications $(n=142)$ With Both major gestational complications $(n=19)$ Without either major gestational complications $(n=115)$ With either major gestational complications $(n=142)$ With Both major gestational complications $(n=19)$ Without either major gestational complications $(n=115)$ With either major gestational complications $(n=142)$ With Both major gestational complications $(n=19)$
Any postpartum cardio-metabolic disease Yes $(n=99)$ RR $(95 \% \mathrm{Cl})$

Reference

$2.7(1.8,4.2)$

$3.6(2.1,6.2)$

Reference

$2.5(1.7,3.9)$

$2.9(1.7,5.1)$

Model 3

$P$-trend $<0.001$

Model 1, unadjusted; Model 2, adjusted for mom age at enrolment, maternal ethnicity, maternal college education, and pre-pregnancy BMI; Model 3, Model $2+$ cumulative parity.

$\mathrm{Cl}$, confidence interval; GDM, gestational diabetes mellitus; HDP, hypertensive disorders of pregnancy; HTN, hypertension; MetS, metabolic syndrome; $\mathrm{RR}$, relative risk.

periods of time. The significant dose-response association between episodes of GDM and postpartum abnormal glucose tolerance in our study is in accordance with Beharier and coworkers (13), even after we adjusted for weight gain during a 5-year interval for model robustness testing. We agreed with Beharier and coworkers that mothers with more than one episode of GDM in all live births represented a higher degree of insulin resistance and $\beta$-cell dysfunction, which more likely resulted in prediabetes and diabetes than mothers without or only one episode of GDM.

GDM and HDP are two major common pregnancy complications throughout pregnancy $(1,2,3)$. Women with GDM were more prone to insulin resistance later in life, which underlies the development of metabolic disorders such as MetS, pre-diabetes and T2D (6, 10, $16,28,29)$. Women with HDP - mainly gestational hypertension and preeclampsia - were more susceptible to prolonged vascular endothelial dysfunction $(30,31)$ or cardiovascular outcomes including hypertension and cardiovascular diseases later in life (3). Even though GDM and HDP may appear to be unrelated, due to their distinctly different clinical manifestation and diagnostic criteria, researchers speculate that glucose intolerance might affect vascular dysfunction and vice versa (18, 30, 32). Furthermore, both gestational complications share common risk factors such as maternal age, parity and pre-pregnancy BMI, that could imply that they may also share pathophysiological changes predisposing to subsequent recurrence of pregnancy complications and postpartum cardio-metabolic disorders over the long term $(18,32)$. However, our findings from this study sample do not support GDM and HDP sharing risks for postpartum glucose metabolism disorders or HTN. We found that mothers with prior GDM were at risk of deterioration of glucose metabolism including fasting and 2-h glucose level and development of pre-diabetes and T2D, yet not at risk of CVD risks including CRP, BP, high cholesterol or development of MetS or HTN. Similarly, mothers with prior HDP were only at risk of development of postpartum HTN, and peripheral vascular resistance including SBP and DBP, yet not at the risk of any metabolic risks. In addition, we observed that mothers with either or combined history of GDM and HDP had similar magnitude of increased risks of developing any cardio-metabolic disease than mothers with neither gestational complication. Even though it is well known that GDM and HDP identify women at high vascular risk, we did not observe a synergistic effect of co-existing pregnancy complications on the risk of developing any cardio-metabolic diseases. This might be attributed to a small sample size, which lacks statistical power to detect different effect sizes between individual and combined GDM and HDP groups. Future studies with either a longer follow-up period or a larger sample size, are therefore warranted to address this issue.

The strength of our study includes a prospective study design and a reasonable response rate (78\%). Detailed information on pregnancy, birth outcomes and detailed past history of all episodes of GDM and HDP were collected in a chronological sequence. Maternal postpartum cardiometabolic diseases including MetS, abnormal glucose metabolism and HTN were diagnosed according to standard WHO or ATP guidelines. All cardio-metabolic risk assessments followed standardized protocols. However, there are limitations that one should bear in mind when interpreting our findings. First, baseline GDM diagnosis 
was defined by WHO 1999 guidelines, which only requires fasting and 2-h glucose testing after a $75 \mathrm{~g}$ oral glucose intake. As it has been suggested that IADSPG criteria may be more sensitive in identifying mild glucose intolerance during pregnancy, GDM cases may be misclassified. Second, even though we have calculated weight gain or weight retention between baseline and 5-year follow-up, we were not able to collect detailed weight gain after each pregnancy from each mother. The rough estimation of weight retention might not be accurate. Third, our samples were purposely selected with 1:1 ratio of mothers with and without GDM at baseline, and therefore, the estimated magnitudes of relative risks may restrict the generalizability of our findings to the general pregnant women population where the prevalence of GDM is much less than 50\%. Fourth, our data on history of GDM and HDP were based on self-reports, and we could not collect accurate information on medication history for both GDM and HDP during pregnancy. Therefore, recall bias and residual confounding (e.g. medication due to GDM and/or HDP during pregnancy) may have potentially affected our study findings. Finally, as some mothers with an episode of GDM and/or HDP did not or were not able to conceive subsequently, our findings could have underestimated the risks under investigation.

\section{Conclusion}

In summary, this study shows evidence of an individual yet not synergic contribution of GDM and HDP to the risk of postpartum cardio-metabolic diseases. Our findings suggest that GDM and HDP represent distinctly different pathogeneses during pregnancy and are associated with increased risk of different cardio-metabolic diseases later in life, without evidence of synergy.

\section{Supplementary data}

This is linked to the online version of the paper at https://doi.org/10.1530/ EC-17-0359.

\section{Declaration of interest}

The authors declare that there is no conflict of interest that could be percieved as prejudicing the impartiality of the research reported.

\section{Funding}

This study entitled as 'Gestational Diabetes Mellitus and Risk of Postpartum Metabolic Syndrome' is funded by Singapore National Medical Council (NMRC/CNIG/1114/2013). Dr Ling-Jun Li is funded by Singapore National
Medical Council Transition Award (NMRC TA/0027/2014) and NMRC/CG/ C008A/2017_KKH.

\section{Author contribution statement}

L-J L designed the study, conducted the whole study, performed data analyses and wrote the manuscript. I M A reviewed and edited the manuscript. L L S reviewed and edited the manuscript. Y S C reviewed the manuscript and provided research data. T Y W reviewed the manuscript and supervised the study design. K K T designed the study, reviewed and edited the manuscript. J J W reviewed the manuscript, contributed to the discussion and edited the manuscript.

\section{Acknowledgements}

The authors thank all mothers for participating in this study, and the GUSTO study team for running this study.

\section{References}

1 Damm P, Houshmand-Oeregaard A, Kelstrup L, Lauenborg J, Mathiesen ER \& Clausen TD. Gestational diabetes mellitus and longterm consequences for mother and offspring: a view from Denmark. Diabetologia 201659 1396-1399. (https://doi.org/10.1007/s00125016-3985-5)

2 Gongora MC \& Wenger NK. Cardiovascular complications of pregnancy. International Journal of Molecular Sciences 201516 23905-23928. (https://doi.org/10.3390/ijms161023905)

3 Naderi S, Tsai SA \& Khandelwal A. Hypertensive disorders of pregnancy. Current Atherosclerosis Reports 2017 19 15. (https://doi. org/10.1007/s11883-017-0648-z)

4 Retnakaran R, Austin PC \& Shah BR. Effect of subsequent pregnancies on the risk of developing diabetes following a first pregnancy complicated by gestational diabetes: a population-based study. Diabetic Medicine 201128 287-292. (https://doi.org/10.1111/ j.1464-5491.2010.03179.x)

5 Buchanan TA \& Xiang AH. Gestational diabetes mellitus. Journal of Clinical Investigation 2005115 485-491. (https://doi.org/10.1172/ JCI200524531)

6 Albareda M, Caballero A, Badell G, Piquer S, Ortiz A, de Leiva A \& Corcoy R. Diabetes and abnormal glucose tolerance in women with previous gestational diabetes. Diabetes Care 200326 1199-1205. (https://doi.org/10.2337/diacare.26.4.1199)

7 Kasher-Meron M \& Grajower MM. Preventing progression from gestational diabetes mellitus to diabetes: a thought-filled review. Diabetes/Metabolism Research and Reviews 201733 7. (https://doi. org/10.1002/dmrr.2909)

8 Kim C, Berger DK \& Chamany S. Recurrence of gestational diabetes mellitus: a systematic review. Diabetes Care 200730 1314-1319. (https://doi.org/10.2337/dc06-2517)

9 Gunderson EP, Jacobs DR Jr, Chiang V, Lewis CE, Feng J, Quesenberry CP Jr \& Sidney S. Duration of lactation and incidence of the metabolic syndrome in women of reproductive age according to gestational diabetes mellitus status: a 20-Year prospective study in CARDIA (Coronary Artery Risk Development in Young Adults). Diabetes 201059 495-504. (https://doi.org/10.2337/db09-1197)

10 Lauenborg J, Mathiesen E, Hansen T, Glumer C, Jorgensen T, BorchJohnsen K, Hornnes P, Pedersen O \& Damm P. The prevalence of the metabolic syndrome in a danish population of women with previous gestational diabetes mellitus is three-fold higher than in the general population. Journal of Clinical Endocrinology and Metabolism 200590 4004-4010. (https://doi.org/10.1210/jc.2004-1713)

11 Bellamy L, Casas JP, Hingorani AD \& Williams D. Type 2 diabetes mellitus after gestational diabetes: a systematic review and 
meta-analysis. Lancet 2009373 1773-1779. (https://doi.org/10.1016/ S0140-6736(09)60731-5)

12 Hanna FW \& Peters JR. Screening for gestational diabetes; past, present and future. Diabetic Medicine 200219 351-358. (https://doi. org/10.1046/j.1464-5491.2002.00684.x)

13 Beharier O, Shoham-Vardi I, Pariente G, Sergienko R, Kessous R, Baumfeld Y, Szaingurten-Solodkin I \& Sheiner E. Gestational diabetes mellitus is a significant risk factor for long-term maternal renal disease. Journal of Clinical Endocrinology and Metabolism 2015100 1412-1416. (https://doi.org/10.1210/jc.2014-4474)

14 Dukler D, Porath A, Bashiri A, Erez O \& Mazor M. Remote prognosis of primiparous women with preeclampsia. European Journal of Obstetrics and Gynecology and Reproductive Biology 200196 69-74. (https://doi.org/10.1016/S0301-2115(00)00392-4)

15 Xiong X, Saunders LD, Wang FL \& Demianczuk NN. Gestational diabetes mellitus: prevalence, risk factors, maternal and infant outcomes. International Journal of Gynecology and Obstetrics 200175 221-228. (https://doi.org/10.1016/S0020-7292(01)00496-9)

16 Ben-Haroush A, Yogev Y \& Hod M. Epidemiology of gestational diabetes mellitus and its association with Type 2 diabetes. Diabetic Medicine 200421 103-113. (https://doi.org/10.1046/j.14645491.2003.00985.x)

17 Ehrenthal DB, Maiden K, Rogers S \& Ball A. Postpartum healthcare after gestational diabetes and hypertension. Journal of Women's Health 201423 760-764. (https://doi.org/10.1089/jwh.2013.4688)

18 Solomon CG \& Seely EW. Brief review: hypertension in pregnancy : a manifestation of the insulin resistance syndrome? Hypertension 2001 37 232-239. (https://doi.org/10.1161/01.HYP.37.2.232)

19 Li LJ, Cheung CY, Ikram MK, Gluckman P, Meaney MJ, Chong YS, Kwek K, Wong TY \& Saw SM. Blood pressure and retinal microvascular characteristics during pregnancy: growing up in Singapore Towards Healthy Outcomes (GUSTO) Study. Hypertension 201260 223-230. (https://doi.org/10.1161/ HYPERTENSIONAHA.112.195404)

20 World Health Organization. Definition, diagnosis and classification of diabetes mellitus and its complications. Geneva, Switzerland: WHO. (available at: http://apps.who.int/iris/ bitstream/10665/66040/1/WHO_NCD_NCS_99.2.pdf)

21 Expert Panel on Detection, Evaluation, and Treatment of High Blood Cholesterol in Adults. Executive summary of the third report of the National Cholesterol Education Program (NCEP) expert panel on detection, evaluation, and treatment of high blood cholesterol in adults (Adult Treatment Panel III). JAMA 2001285 2486-2497.

22 World Health Organization. Screening for type 2 diabetes. Geneva, Switzerland: WHO. (available at: http://www.who.int/diabetes/ publications/en/screening_mnc03.pdf)
23 Cohen RM, Haggerty S \& Herman WH. HbA1c for the diagnosis of diabetes and prediabetes: is it time for a mid-course correction? Journal of Clinical Endocrinology and Metabolism 201095 5203-5206. (https://doi.org/10.1210/jc.2010-2352)

24 Pillai A, Sharma D \& Kadam P. Hypertension in the neonatal period: an update. Current Hypertension Reviews 201612 186-195. (https:// doi.org/10.2174/1573402112666161129155224)

25 Winhofer Y, Tura A, Prikoszovich T, Winzer C, Schneider B, Pacini G, Luger A \& Kautzky-Willer A. The impact of recurrent gestational diabetes on maternal metabolic and cardiovascular risk factors. European Journal of Clinical Investigation 201343 190-197. (https:// doi.org/10.1111/eci.12031)

26 Xiang AH, Kawakubo M, Trigo E, Kjos SL \& Buchanan TA. Declining beta-cell compensation for insulin resistance in Hispanic women with recent gestational diabetes mellitus: association with changes in weight, adiponectin, and C-reactive protein. Diabetes Care 201033 396-401. (https://doi.org/10.2337/dc09-1493)

27 England L, Kotelchuck M, Wilson HG, Diop H, Oppedisano P, Kim SY, Cui X \& Shapiro-Mendoza CK. Estimating the recurrence rate of Gestational Diabetes Mellitus (GDM) in Massachusetts 1998-2007: methods and findings. Maternal and Child Health Journal 201519 2303-2313. (https://doi.org/10.1007/s10995-015-1750-x)

28 Kousta E, Efstathiadou Z, Lawrence NJ, Jeffs JA, Godsland IF, Barrett SC, Dore CJ, Penny A, Anyaoku V, Millauer BA, et al. The impact of ethnicity on glucose regulation and the metabolic syndrome following gestational diabetes. Diabetologia 200649 36-40. (https://doi.org/10.1007/s00125-005-0058-6)

29 Tobias DK, Stuart JJ, Li S, Chavarro J, Rimm EB, Rich-Edwards J, Hu FB, Manson JE \& Zhang C. Association of history of gestational diabetes with long-term cardiovascular disease risk in a large prospective cohort of US women. JAMA Internal Medicine 2017177 1735-1742. (https://doi.org/10.1001/ jamainternmed.2017.2790)

30 Carpenter MW. Gestational diabetes, pregnancy hypertension, and late vascular disease. Diabetes Care 200730 (Supplement 2) S246-S250. (https://doi.org/10.2337/dc07-s224)

31 Yinon Y, Kingdom JC, Odutayo A, Moineddin R, Drewlo S, Lai V, Cherney DZ \& Hladunewich MA. Vascular dysfunction in women with a history of preeclampsia and intrauterine growth restriction: insights into future vascular risk. Circulation 2010122 1846-1853. (https://doi.org/10.1161/CIRCULATIONAHA.110.948455)

32 Vambergue A, Nuttens MC, Goeusse P, Biausque S, Lepeut M \& Fontaine P. Pregnancy induced hypertension in women with gestational carbohydrate intolerance: the diagest study. European Journal of Obstetrics and Gynecology and Reproductive Biology 2002102 31-35. (https://doi.org/10.1016/S0301-2115(01)00556-5)

Received in final form 30 January 2018

Accepted 14 February 2018

Accepted Preprint published online 14 February 2018 http://www.endocrineconnections.org https://doi.org/10.1530/EC-17-0359
(C) 2018 The authors Published by Bioscientifica Ltd
This work is licensed under a Creative Commons Attribution-NonCommercial-NoDerivatives 4.0 International License. 